\title{
BIOCHEMICAL AND CULTURAL CHARACTERISTICS OF PASTEURELLA HAEMOLYTICA ISOLATED FROM PNEUMONIC LUNGS OF GOATS
}

\author{
N.U. HORADAGODA, ${ }^{1 *}$ M.C.L. DE ALWIS, ${ }^{2}$ S.G. DE S. WETTIMUNY ${ }^{1}$ and \\ A.A. VIPULASIRI ${ }^{2}$ \\ 1 Faculty of Veterinary Medicine and Animal Science, University of Peradeniya, \\ Peradeniya. \\ 2 Veterinary Research Institute, Peradeniya.
}

(Received: 25 August 1993 ; accepted: 15 November 1994)

\begin{abstract}
The cultural characteristics and biochemical reactions of 50 strains of $P$. haemolytica isolated from pneumonic lungs of goats were studied. All strains produced a zone of beta haemolysis on blood agar prepared from either bovine or sheep blood with no apparent difference in colony morphology. A large number of strains failed to grow on MacConkey agar unless the medium was enriched with goat serum. The biochemical reactions of all strains were uniform, and closely resembled the reference strains of $P$. haemolytica isolated from sheep. They were positive for catalase, oxidase and nitrate, and negative for urease, indole and hydrogen sulphide; the strains failed to liquefy gelatin. In the fermentation reactions, all strains fermented glucose, maltose, mannitol, xylose and sorbitol with the production of acid only. The reaction with lactose, salicin and arabinose varied between strains. None of the strains fermented adonitol, dulcitol and trehalose.
\end{abstract}

Key words: Goat, Pasteurella haemolytica, pneumonia, respiratory diseases.

\section{INTRODUCTION}

Pasteurella haemolytica is an important bacterial pathogen associated with respiratory tract infections in domestic ruminants worldwide. In cattle, the organism is identified as the primary agent responsible for pneumonic pasteurellosis, a common and economically important disease in intensively managed animals in Western Europe ${ }^{1}$ and North America. ${ }^{2}$ In sheep, P. haemolytica causes a wide variety of diseases which include pneumonia in all age groups, septicaemia in weaned lambs and mastitis in ewes. ${ }^{3}$ In both tropical and temperate countries the organism is also associated with pneumonia in goats ${ }^{4-10}$ and several workers have reproduced the disease experimentally. ${ }^{7,8,11}$ In Sri Lanka; $P$. haemolytica was reported for the first time when the organism was isolated from approximately 75 per cent of goat pneumonic lungs collected from an abattoir. ${ }^{12}$.Subsequently, the organism was implicated in a field outbreak of caprine pneumonia.$^{13}$

$P$. haemolytica can be classified into two biotypes on the basis of several criteria including nucleic acid homology, ${ }^{14}$ antibiotic sensitivity, ${ }^{15}$ and carbohydrate fermentation reactions. ${ }^{16}$ The organisms that ferment arabinose are grouped as biotype A and those that ferment trehalose as biotype T. Clinically, the A biotypes are associated with pneumonic pasteurellosis and the T biotypes with systemic disease in weaned lambs. Sixteen serotypes of $P$. haemolytica are

\footnotetext{
* Corresponding author.
} 
differentiated by the indirect haemagglutination test which depends on the capsular antigen of the bacterium. ${ }^{17-19}$

Studies relating to the growth characteristics of $P$. haemolytica are based primarily on strains isolated from cattle and sheep in temperate countries. ${ }^{20-23}$ These investigations recorded considerable diversity in the cultural and fermentation reactions of the organism. ${ }^{21}$ Biberstein et al. ${ }^{20}$ considered the following criteria in order of diminishing importance for the species, a) haemolysis on beef blood agar, b) absence of indole production, c) growth on MacConkey agar, d) failure to reduce methylene blue milk and e) fermentation of glucose and sucrose with the production of moderate acidity. Subsequent studies of the organism isolated from cattle ${ }^{23}$ as well as from sheep ${ }^{22}$ recorded further variations in the cultural and biochemical characteristics that are relevant in identifying the organism. Although $P$. haemolytica has been frequently isolated from respiratory infections in goats, especially in the tropical countries, relatively little is known of the growth characteristics of the organism when compared to isolates obtained from cattle and sheep in temperate countries. The objective of the present paper is to describe the cultural characteristics and, the biochemical and fermentation reactions of $P$. haemolytica isolated from the pneumonic lungs of goats in Sri Lanka.

\section{METHODS AND MATERIALS}

Bacterial cultures: A total of 50 strains of $P$. haemolytica isolated from goat pneumonic lungs which were collected at the Colombo municipal abattoir were used in this study. The methods used for isolation were as described previously. ${ }^{12}$ The cultures were preserved in semi solid nutrient agar stabs at room temperature until the time of examination.

Cultural characters: All isolates were grown on 5 per cent sheep blood agar, MacConkey agar (Difco) and MacConkey agar enriched with 5 per cent goat serum. Additionally, the cultural characteristics of ten randomly selected isolates were examined on 5 per cent bovine blood agar.

Biochemical tests: Cultures in nitrate medium were tested at 48 hours for the presence of nitrite. Indole production was examined in 48 hour peptone water cultures using Kovac's reagent. The motility was tested in SIM medium (Difco). Gelatin liquefaction was evaluated in $15 \%$ nutrient gelatin. Stabs were incubated at $37^{\circ} \mathrm{C}$. for one week and readings were taken after placing the stabs at $4^{\circ} \mathrm{C}$ for 30 minutes. Hydrogen sulphide production was tested on triple sugar iron agar and SIM medium. Oxidase, catalase and urease tests were performed as decribed by Carter and Cole. ${ }^{24}$

Fermentation reactions: The fermentation reactions were carried out in the medium recommended by Biberstein and Gills ${ }^{25}$ which consisted of Bacto peptone ( $10 \mathrm{~g}$; Difco), sodium chloride $(5 \mathrm{~g})$ and Bacto beef extract ( $4 \mathrm{~g}$; Difco) in 1 litre of distilled water. One $\mathrm{ml}$ of Bromocresol purple (1.6g in 95\% ethanol) was added as an indicator and the $\mathrm{pH}$ was adjusted to 7.1 . The substrates used 
were arabinose, adonitol, glucose, lactose, maltose, mannitol, salicin, sorbitol, trehalose and xylose. The organism was inoculated into a one per cent solution of substrate in the fermentation medium and incubated at $37^{\circ} \mathrm{C}$ for 14 days.

The change of the indicator colour from purple to yellow was checked daily by visual comparision with a non-inoculated vial as control. For purposes of comparison, biochemical and fermentation tests were carried out simultaneously with reference strains of biotypes $\mathrm{A}$ and $\mathrm{T}$ isolated from sheep (culture numbers $\mathrm{A} 3$ and 863 described by Biberstein and Gills ${ }^{25}$ ).

\section{RESULTS}

\section{Cultural and morphological characteristics}

Growth on bovine and sheep blood agar was observed within 48 hours of incubation at $37^{\circ} \mathrm{C}$. In both media, the colonies were round, grayish, flattened and glistening with entire edges. The diameter of the colonies varied from 0.5 to $1.5 \mathrm{~mm}$. and they were surrounded by a narrow, clear zone of beta haemolysis. There were no apparent differences in the cultural characteristics when strains were grown either on bovine or sheep blood agar. Most isolates failed to grow on MacConkey agar when incubated for $24 \mathrm{~h}$ at $37^{\circ} \mathrm{C}$. However, concave, round pale pink colonies appeared when the medium was enriched with 5 per cent goat serum and incubated under similar conditions. Microscopical examination of gram-stained smears from colonies revealed small gram-negative rods or coccobacilli.

\section{Biochemical characteristics}

The results of the biochemical reactions are presented in Table 1. All isolates were consistent in their reaction and closely resembled the reference strains from sheep. They were positive for catalase, oxidase and reduced nitrate to nitrite. All isolates were negative for urease and failed to liquefy gelatin; none of the isolates produced indole or hydrogen sulphide.

Table 1: Biochemical reactions of $P$. haemolytica isolated from pnuemonic lungs of goats.

\begin{tabular}{lccccccc}
\hline & $\begin{array}{c}\text { Hydrogen } \\
\text { sulphide }\end{array}$ & Nitrate & $\begin{array}{c}\text { Gelatin } \\
\text { Liquefaction }\end{array}$ & Urease & Catalase & Oxidase Indole \\
\hline $\begin{array}{l}\text { No. isolates } \\
\text { tested }\end{array}$ & 50 & 50 & 50 & 50 & 50 & 50 & 50 \\
$\begin{array}{l}\text { No. isolates } \\
\text { positive }\end{array}$ & 0 & 50 & 0 & 0 & 50 & 50 & 0 \\
\hline
\end{tabular}




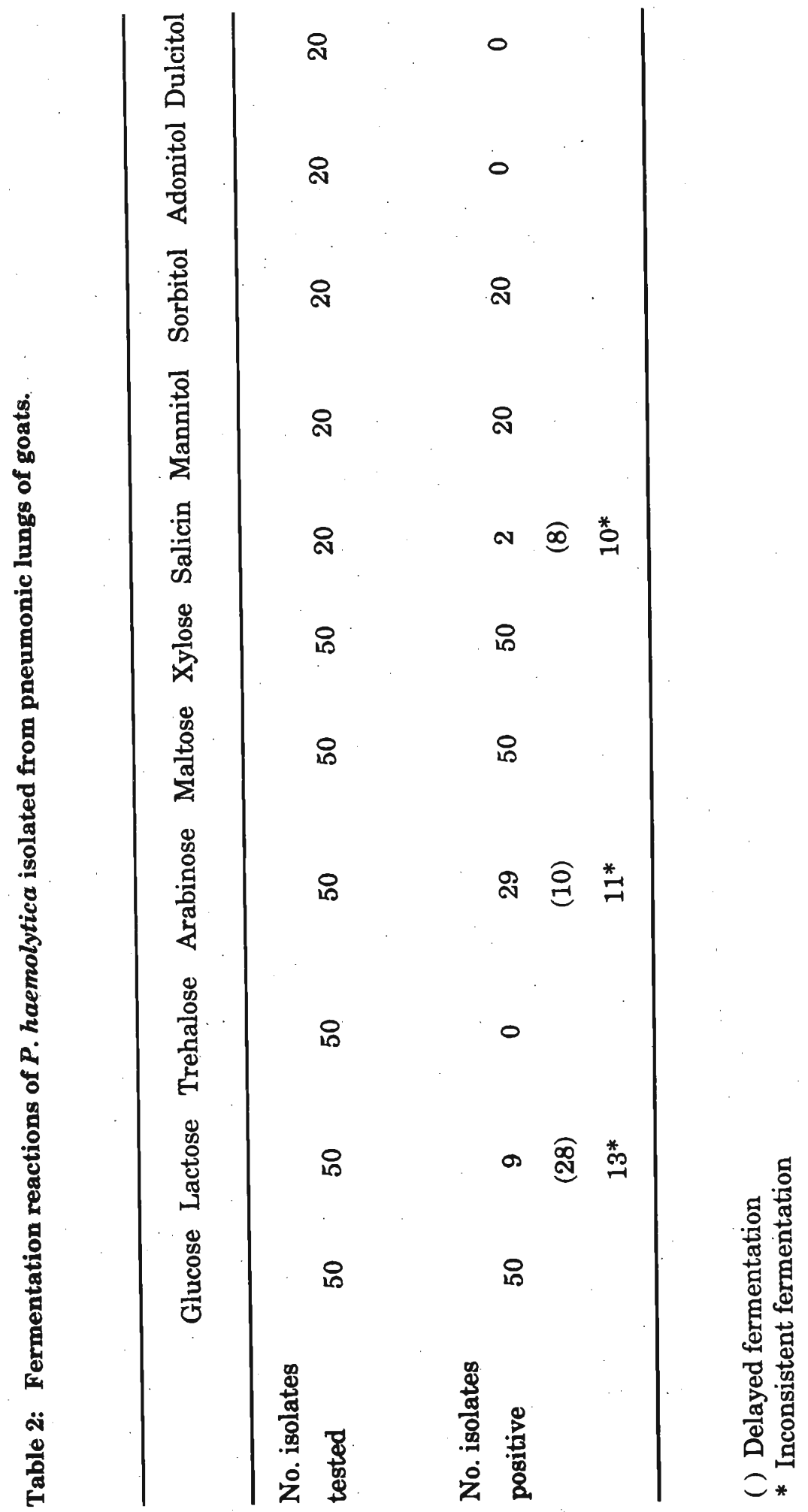




\section{Fermentation reactions}

All strains consistently fermented glucose, maltose, mannitol, xylose and sorbitol with acid formation only (Table 2). The isolates did not ferment trehalose, adonitol or dulcitol. The fermentation reaction with lactose, salicin and arabinose were variable with some strains showing a delayed fermentation and others displaying an inconsistent fermentation reaction. None of the isolates gave acidification in control medium without fermentable substrate.

\section{DISCUSSION}

The identification of $P$. haemolytica, particularly in developing countries is based on the cultural characteristics and biochemical reactions of the organism while serotyping is often restricted to specialist laboratories. Although $P$.haemolytica is recognised as an important bacterial pathogen responsible for respiratory tract infections in goats most of the information on the growth characteristics of the organism are based on studies conducted in cattle and sheep.

Haemolysis on blood agar is regarded as an important criterion in differentiating $P$. haemolytica from other species of Pasteurellae, especially P. multocida which is also known to be associated with pneumonia in goats. ${ }^{26}$ According to Cammeron ${ }^{27}$ haemolysis produced by $P$. haemolytica is dependent on the type of blood used; bovine blood agar was found to be the best to demonstrate haemolysis while sheep blood was suitable only when washed cells were used instead of whole blood. In the studies by Cammeron, ${ }^{27}$ equine blood was found to be unsuitable to observe haemolyis produced by the organism. The fact that washed sheep red cells are susceptible to haemolysis indicates that the haemolysis effect may be due to the presence of serum antibodies, although with equine blood, the washed red cells still remained resistant to haemolysis suggesting a different mechanism in the latter species. The role of serum antibodies to $P$. haemolytica and its effect in inhibiting haemolysis produced by the organism on blood agar is supported by an earlier observation recorded by Woxhott ${ }^{28}$ who also demonstrated a reduction of the haemolytic zone when antibodies to $P$. haemolytica were present in the blood. In the work reported herein, a clear zone of haemolysis was observed in blood agar prepared from both bovine and sheep blood and it may be due to the absence of antibodies against $P$. haemolytica in the blood used for preparation of the blood agar medium. Unlike in most temperate countries, infections caused by $P$. haemolytica are relatively uncommon among cattle and sheep in Sri Lanka (Thula Wijewardena, personal communication) hence, it is likely that the media prepared from blood collected from animals held within the laboratory premises were devoid of antibodies.

Growth on MacConkey agar is considered as another important cultural characteristic in differentiating $P$. haemolytica from other Pasterellae which inhabit the respiratory tract of goats. However, in the present study a large proportion of the isolates failed to grow on McConkey agar unless the medium was enriched with goat serum. This finding appears to be specific to this study as it has 
not been reported by any of the other workers ${ }^{4,6-8}$ who have isolated $P$. haemolytica from goats. The only related observation in this connection was made by Gourlay and Barber ${ }^{5}$ who noticed a reduction of growth on MacConkey agar when the organism was subcultured from blood agar. In the present study we did not pursue investigations to identify the specific serum constituent which was responsible for the enhanced growth on MacConkey agar but it may be an area worth studying in any future investigations of the organism in Sri Lanka.

The results of the biochemical reactions observed in this study are generally in agreement with the findings recorded by $\mathrm{Ojo}^{29}$ for strains of $P$. haemolytica isolated from Nigerian goats and with those reported for isolates from cattle ${ }^{23}$ and sheep. ${ }^{25}$ One exception was that in the studies conducted by $\mathrm{Ojo}^{29}$ a little over 10 per cent of the isolates produced hydrogen sulphide which was not observed in any of the strains we examined or in the isolates from cattle. ${ }^{23}$

The fermentation of glucose, mannitol, sorbitol, maltose and xylose with the production of acid is in agreement with fermentation reactions reported for $P$.haemolytica isolated from cattle ${ }^{23}$ and sheep. ${ }^{22}$ Although A biotypes are associated with pneumonia in cattle and sheep, the fermentation of arabinose by some strains of $P$. haemolytica isolated from goat pneumoniclungs in the present study were inconsistent or delayed. This observation is comparable to the findings of Shreeve et al. ${ }^{22}$ who examined the fermentation reactions with arabinose and trehalose in at least 3 strains for each of the $\mathrm{A}$ and $\mathrm{T}$ biotypes of $P$. haemolytica isolated from sheep. Based on the fermentation of these two carbohydrate substrates, Shreeve et $a l .{ }^{22}$ concluded that the use of the fermentation reactions with arabinose and trehalose to distinguish the $\mathrm{A}$ and $\mathrm{T}$ biotypes was more reliable for $\mathrm{T}$ strains than for A strains since some strains of biotype A failed to ferment arabinose even after 14 days. In the present study none of the isolates fermented trehalose, a fermentation reaction observed with $\mathrm{T}$ biotypes responsible for systemic diseases in lambs. However, in the investigations of $\mathrm{Ojo}^{29}$ almost half the isolates from goat pneumonic lungs fermented trehalose, and in another study ${ }^{11}$ a $\mathrm{T}$ biotype of $P$. haemolytica isolated from a case of acute caprine pneumona was capable of reproducing the disease experimentally when administered as a live culture or as a heat-killed suspension. The latter findings indicate that unlike in sheep and cattle, $\mathrm{T}$ biotypes of $P$. haemolytica are also important in the aetiology of pneumonia in goats. In the present study, the classification of isolates of $P$. haemolytica to A and T biotypes was based only on their ability to ferment arabinose or trehalose. The adoption of tests such as esculin hydrolysis and the fermentation reactions with xylose and mannose would have further assisted in the identification of the biotypes, ${ }^{30}$ but these procedures could not be performed in this study as some of the isolates were lost during storage.

The fermentation of lactose and salicin by $P$. haemolytica seem to vary with the biotype and animal from which the organism has been isolated. In sheep, none of the $T$ biotypes fermented lactose but it was observed in 70 per cent of A biotypes. ${ }^{22}$ According to Wessman and Hiker ${ }^{23}$ all A biotypes isolated from pneumonic lungs of cattle fermented lactose. In the fermentation of salicin, all 
T biotypes from sheep fermented the substrate while it was observed in only about 10 per cent of the A biotypes. ${ }^{22}$ None of the A biotypes from cattle fermented salicin. ${ }^{23}$ In isolates from goats, $\mathrm{Ojo}^{29}$ reported that 25 per cent and 40 per cent of the cultures fermented lactose and salicin, respectively. These results however, were not related to biotypes of $P$. haemolytica. In the present study only a small proportion of the isolates fermented lactose and salicin; a large number of strains showed delayed or inconsistent fermentation.

This study, in general, establishes that strains of $P$. haemolytica isolated from goat pneumonic lungs in Sri Lanka are biochemically similar to those isolated from cattle and sheep in other countries. The need to enrich MacConkey agar with serum in order to enhance growth and variations in the fermentation reactions are significant findings which may have applications in the isolation and identification of the organism from goats.

\section{Acknowledgement}

We thank Professor E.L.Biberstein, University of Califonia, Davis, and Dr. G.H. Frank, National Animal Disease Centre, Iowa, for supplying the typed cultures of $P$. haemolytica. This investigation was supported by a grant from the Natural Resources, Energy and Science Authority.

\section{References}

1. Allan E.M., Gibbs H.A., Wiseman A. \& Selman I.E. (1985). Sequential lesions of experimental bovine pneumonic pasteurellosis. Veterinary Record 117: 438-442.

2. Yates W.D.G. (1982). A review of infectious bovine rhinotracheitis shipping fever pneumonia and viral-bacterial synergism in respiratory disease of cattle. Canadian Journal of Comparative Medicine 46: 225-263.

3. Gilmour N.J.L. (1978). Pasteurellosis in sheep. Veterinary Record 102: $100-102$.

4. Fodor L., Hajtos I. \& Glavits R. (1990). Diseases caused by Pasteurella haemolytica in Hungarian goat herds. Magyar Allatorvosok Lapja 45: 545-548. Veterinary Bulletin (1991) 61: Abstract No. 2389.

5. Gourlay R.N. \& Barber L. (1960). A strain of Pasteurella haemolytica isolated from goats in Uganda. Journal of Comparative Pathology 70: 211- 216.

6. Midwinter A.C., Clarke J.K. \& Alley M.R. (1985). Pasteurella haemolytica serotypes from pneumonic goat lungs. New Zealand Veterinary Journal 34: $35-36$.

7. Mugera G.M. \& Kramer T.T. (1967). Pasteurellosis in Kenya goats due to Pasteurella haemolytica. Bulletin of Epizootic Diseases of Africa 15: 121-131. 
8. Mwangota A.V., Muhammed S.I. \& Thomas R.G. (1978). Serological types of Pasteurella haemolytica in Kenya. Cornell Veterinarian 68: 84-93.

9. Ojo M.O. (1976). Caprine pneumonia in Nigeria. I. Epidemiology and bacterial flora of normal and diseased respiratory tracts. Tropical Animal Health and Production 8: 85-89.

10. Pegram R.G. (1974). Serological types of Pasteurella haemolytica isolates from sheep and goats in the Somali Democratic Republic. Tropical Animal Health and Production 6: 189-191.

11. Ngatia T.A., Kimberling C.V., Johnson L.W., Whiteman C.E. \& Lauermann L.H. (1986). Pneumonia in goats following administration of live and heatkilled Pasteurella haemolytica. Journal of Comparative Pathology 96: 557-664.

12. Horadagoda N.U., De Alwis M.C.L., Wettimuny S.G. de. S., Anthony C.S.V.B. \& Vipulasiri A.A. (1982). Bacteriological studies on normal and pneumonic lungs of goats in Sri Lanka. Ceylon Veterinary Journal 29: 12-13.

13. Balasuriya B.R.U., Maithripala H.A. \& Wanasinghe D.D. (1987). Pneumonia among a herd of goats: possible role of Pasteurella haemolytica. Sri Lanka Veterinary Journal 33: 42-43.

14. Biberstein E.L. \& Francis C.K. (1968). Nucleic acid homologies between A and T types of Pasteurella haemolytica. Journal of Medical Microbiology 1:105-108.

15. Biberstein E.L. \& Kirkham C. (1979). Antimicrobial susceptibility patterns of the A and T types of Pasteurella haemolytica. Research in Veterinary Science 26:324-328.

16. Smith G.R. (1961). The characterisation of two types of Pasteurella haemolytica associated with different pathological conditions in sheep. Journal of Pathology and Bacteriology 81: 431-440.

17. Biberstein E.L. (1978). Biotyping and serotyping of Pasteurella haemolytica. In: (Ed. R. Norris) Methods in Microbiology. Vol. 10. pp. 253-269. Academic Press, New York.

18. Fodor L., Varga J., Haytos I., Donachie W. \& Gilmour N.J.L. (1987). New serotype of $P$. haemolytica isolated in Hungary. Veterinary Record 121: 155.

19. Fraser J., Laird S. \& Gilmour N.J.L. (1982). A new serotype (biotype T) of Pasteurella haemolytica. Research in Veterinary Science 32: 127-128.

20. Biberstein E.L., Gills M. \& KnightH. (1960). Serological types of Pasteurella haemolytica. Cornell Veterinarian 50: 283-300. 
21. Newsom I.E. \& Cross F. (1932). Some bipolar organisms found in pneumonia in sheep. Journal of the American Veterinary Medical Association 80: 711-719.

22. Shreeve B.J., Ivanov I.N. \& Thompson D.A. (1970). Biochemical reactions of different serotypes of Pasteurella haemolytica. Journal of Medical Microbiology 3: 356-358.

23. Wessman G.E. \& Hiker G. (1968). Characterisation of Pasteurella haemolytica isolated from the respiratory tract of cattle. Canadian Journal of Comparative Medicine 32: 498-504.

24. Carter G.R. \& Cole J.R. (1990). Diagnostic Procedures in Veterinary Bacteriology and Mycology. 5th Edition. Academic Press Inc., London.

25. Biberstein E.L. \& Gills M. (1962). The relation of the antigenic types to the A and T types of Pasteurella haemolytica. Journal of Comparative Pathology 72: $316-320$.

26. Ugochukwu E.I. (1983). Pathology of bacterial pneumonia of goats in Nsukka and Enugu zones of Anambra states, Nigeria. Bulletin of Animal Health and Production in Africa 31: 343-347.

27. Cammeron J. (1965). Differentiation of Pasteurella haemolytica and Pasteurella multocida (Pasteurella septica). Veterinary Record 77: 968.

28. Woxhott L. (1954). Undersokelser over haemolysindannelsen hos Pasteurella haemolytica. Nordisk Veterinarmedicin 6: 344-354.

29. Ojo M.O. (1975). Caprine pneumonia III. Biochemical characterisation and serological types of Pasteurellae. Nigerian Journal of Animal Production 2: 216-221.

30. Manual of Clinical Microbiology (1991). 5th Edition. Albert Balows, Washington D.C. p. 426. 